\title{
Discussion on the Coordinated Development of Ecological Protection and Tourism Development from the Current Situation of Country Park in Shenzhen
}

\author{
$\mathrm{Hu}^{1}{ }^{1}$ and Huang $\mathrm{Hui}^{2, a}$ \\ ${ }^{1}$ Lecturer of Shenzhen Polytechnic, China \\ ${ }^{2}$ Associate Professor of Shenzhen Polytechnic, China
}

\begin{abstract}
Country parks consist of an important part of the urban green space construction system, which have a dual function of ecological protection and tourism. It is difficult to maintain an equilibrium between ecological protection and tourism development when it comes to the construction of country parks. Shenzhen has obtained great results in the construction of country parks, even thou some problems were encountered. Basing on the principles of ecological protection, this paper puts forward a combination of planning design and tourism planning, while fully considering the fundamental needs of tourism, in order to improve the construction of the country park facilities
\end{abstract}

\section{Country Park Development}

With the rapid economical development and the accelerated process of urbanization, the city environment is continuously deteriorating. Due to the lack of new urban development space, the urban sprawl has become increasingly prominent. The green space surrounding the cities have been occupied, the suburban living environment has been destroyed, and the biological diversity has also been threatened in many situations. To solve this problem in cities, building country park is a practical and efficient way.

The concept of country parks originated from the National Parks in the United States, which was set up in order to protect the natural environmental resources, the ecological systems, and the cultural and historical sites. The principle of country parks was first put forward by Britain, whose aim is to make people conveniently the suburb recreation, while reducing the destruction of rural resources, and protecting the rural landscape resources. According to Wikipedia: "A country park is an area designated to visit and enjoy recreation in a countryside environment ${ }^{[1] "}$. In China, Hong Kong is the earliest city that has set up country parks, it is also the city that has the most successful and mature constructions of country parks. The emergence of country parks in Hong Kong came along the rapid economical development and urban expansion of the city. Country parks are established in goal of protecting the local natural environment resources and providing leisure recreation and natural education to the citizens. The Hong Kong country park concepts and systems have a quite deep influence on the construction of country parks in Mainland China.

\footnotetext{
${ }^{a}$ Corresponding author : Huang Hui, 641602451@qq.com
} 
Because of the particularity in its geographical position, country parks are different from the traditional city parks, forest parks, and natural reserves. The location of country parks are selected mainly for its advantages in ecological protection. Tourism attraction and scientific education are supplemental characteristics. The key point is to protect the natural landscape resources, to improve the ecological conditions, to protect the diversity of the species, and to reduce the destruction of natural ecological environment done by urban expansion. As a new type of park in China, the construction and practice of country parks lack experiences. It is still in exploration and trial stage, a complete set of method system in planning and construction is lacking. Therefore, many problems have emerged in the construction of the existing country parks. Taking the construction of country park in Shenzhen as an example, this paper discusses the coordinated development of ecological protection and tourism planning in the construction of country parks, and hopes to promote the construction and sustainable development of country parks.

\section{Shenzhen Country Park Construction Status}

\subsection{Shenzhen Country Park planning and distribution status}

In order to develop the external ecological green space for the city's ecological conservation, Shenzhen is one of cities in China that start early on country park planning and construction. In "Green Shenzhen Urban Development Plan ( 2010-2020 ) " published in 2012, a total delineated plan includes Tang Long Shan Country Park, Ma Luan Shan Country Park, Yang Tai Shan Country Park, Qi niang Shan Country Park and others 21 Country Parks ( FIG. 1 ), covering the city's six districts , with a total area of $680.7 \mathrm{KM}^{2}{ }^{22]}$, accounting for $13 \%$ of the total area of Shenzhen and $27 \%$ of the city's total forest area. Until now, 7 country parks have been built.

Shenzhen country parks are concentrated in the eastern coasts and the northern mountainous area of the city, which form an east -to-west oriented ecological corridor. In the recreation space system, country parks are mainly responsible for the ecological conservation, natural resources protection, recreation, and the control of urban spatial culture at the same time ${ }^{[3]}$.

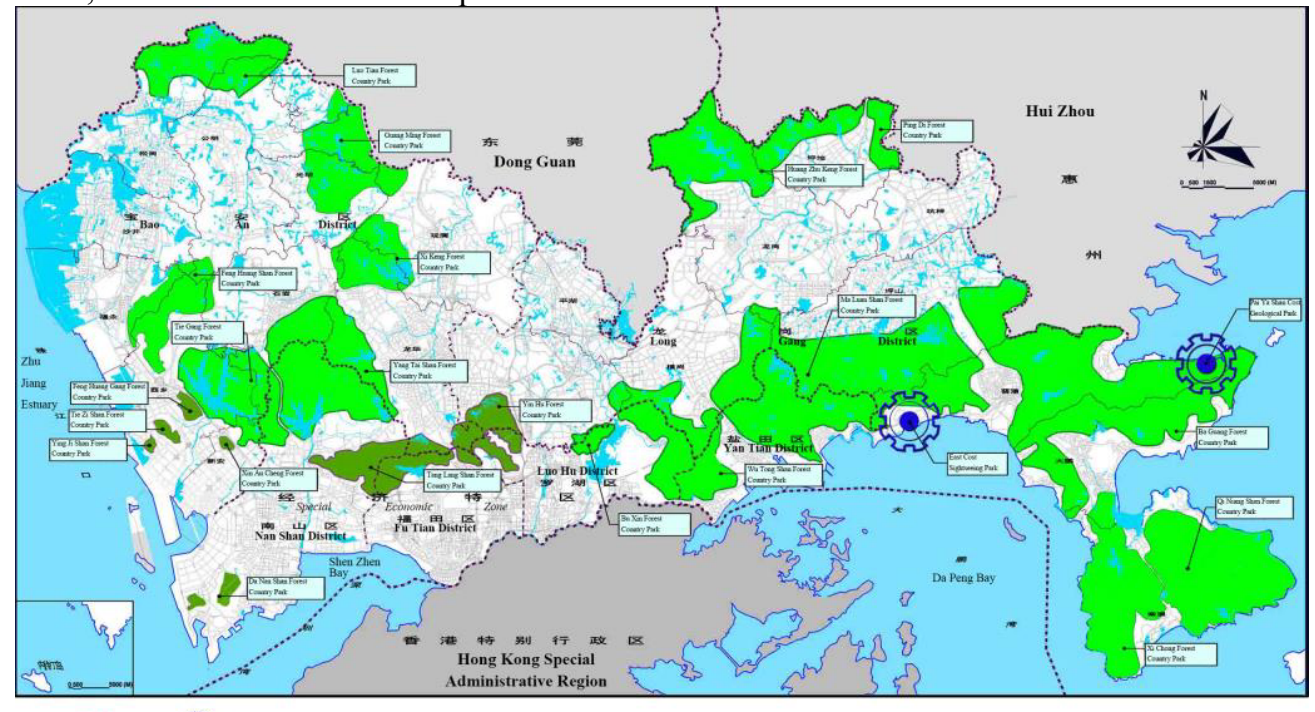

Legend $\square$ Water

Figure 1. Shenzhen Country Park Map ${ }^{[4]}$

"Green Shenzhen Urban Development Plan ( 2010-2020 ) " mentioned that " Forest Country Park to protect the ecological construction, mainly to provide recreational activities and leisure facilities , supplemented by strict conservation of biological diversity, ecological resources and the countryside 
to watch value, is a prerequisite for development and construction" . In the beginning of planning, Shenzhen country parks are designed on the basic principles of ecological protection, in terms of natural resources, plant resources, animal resources, landscape and cultural resources to provide a detailed analysis on Shenzhen green space system. Basing on the survey of natural and human resources, evaluation, use of ecological suitability, ecological sensitivity index, slope geological hazard and the ecological carrying capacity of each country parks and other ecological function zonings, a distinction between the country resort and the ecological protection zone has been made, in accordance to the core area of ecology and the ecological restoration zone zoning plan.

Shenzhen Country Park Planning and Construction is a prerequisite for development of ecological protection planning. Ecological protection is the most important and the core aspect. The evaluation of landscape value are carried out in this context, but in terms of country parks, tourism and leisure also are very important aspects. It is also very critical in term of the perspective of tourism, interpretation and understanding of tourism resources with ecological protection needs, to enhance the overall resort.

\subsection{Investigation on the tourism demand in Shenzhen country parks}

Landscape value, price formulation and location choice of country park are key factors in the planning. Study found that a certain degree of preference to the functional types of the recreational product by the visitors can be expressed by the price, distance, and other factors. However, effective information extracted from the recreation preference survey, as well as the amount of empirical studies made to provide basis and suggestion to the country park planning are very few in the planning and designs of country parks in China ${ }^{[5]}$. Shang Fengbiao carried out a questionnaire survey for residents in 8 cities in China. After having analyzed the types of country parks, demands, management systems provided, service contents, etc, Shang Fengbiao have put forward 6 elements to construct the development system of country parks ${ }^{[6]}$. A questionnaire survey on the behavior characteristics of tourists in 2 Shenzhen country parks was carried out by Zhu Jiang. Statistics on tourists travel time, method, time spend, motivation, behaviors, activity type, and other indicators have been collected in percentages ${ }^{[7]}$. Table 2 provides the description on tourists' demands. Suggestions for the country park recreation facilities have also been put forward.

In seven country parks which have been built in Shenzhen, we conducted a survey of visitors . The survey contains the basic attributes of tourists, behavioral characteristics, satisfaction with three top items, subdivided into ten sub items.

\subsubsection{Country Park Visitor basic properties (Table 1)}

( 1 ) Gender structure : Male to female ratio close to $2: 1$;

( 2 ) Age structure : 88\% of young, barely 65 years old;

( 3 ) Education: mainly High school and college;

( 4 ) Income Characteristics : mainly middle-income;

( 5 ) source distribution : mainly urban residents.

Table 1. Country Park Visitor basic properties.

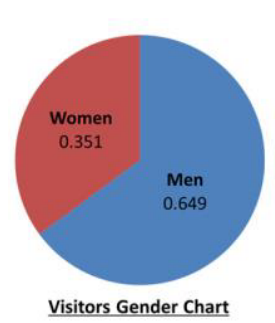

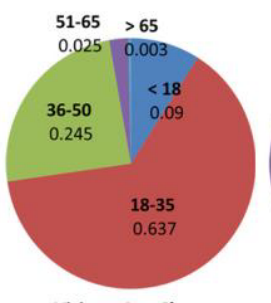

Visitors Age Chart

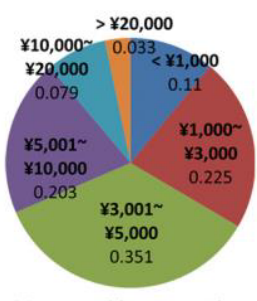

Visitor Monthly Income Chart

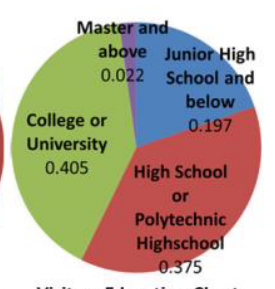

Visitors Education Chart 


\subsubsection{Tourists' Behavior Characteristics (Table 2)}

( 1 ) Visiting purpose : visiting and fitness .

(2) Visiting frequency : revisit higher.

( 3 ) Duration of visits : mainly half-day, day trips.

( 4 ) Events feature : mainly mountain climbing, secondly riding.

( 5 ) Consumer features : mainly low consumption and zero consumption.

Table 2. Tourists' Behavior Characteristics.

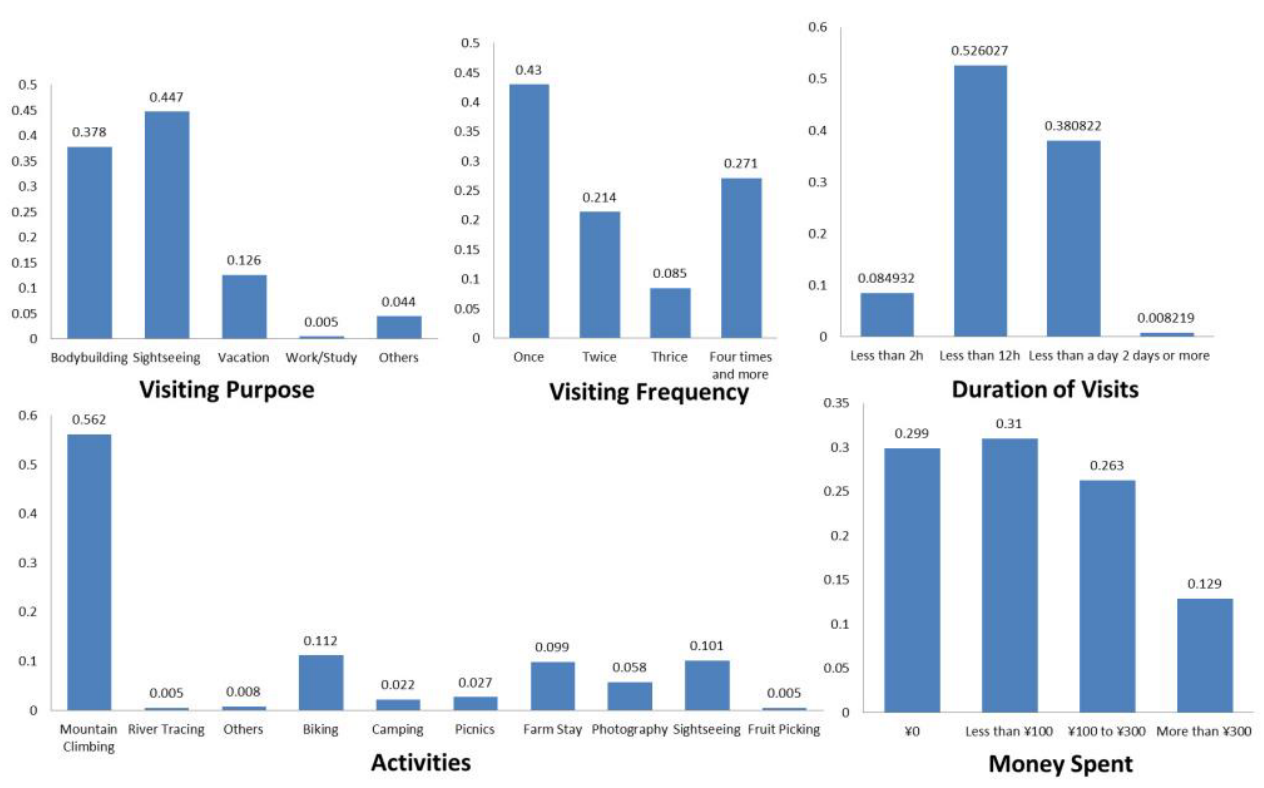

\subsubsection{Visitor reception status}

( 1 ) Analysis of tourist satisfaction: overall satisfaction : $65 \%$; dissatisfied focus areas: identification system.

( 2 ) Analysis of the number of visitors : tourists is growing rapidly; Country Park is very obvious seasonal tourism, tourist busy season is from September to May of the following year; the tourist low season is from June to August each year. Tourism has entered the second stage of the life cycle.

( 3 ) According to the tourism life cycle theories, by Butler, the Shenzhen Country Park is basically in "participatory phase", the amount of tourists is increasing, locals are offering tourist infrastructure.

\subsection{Problems in Shenzhen Country Parks}

(1) serious recreation project homogeneity

(2) serious lack of service facilities and safety facilities

(3) imperfect the traffic system

(4) intelligent management system is not yet popularized

\subsection{The root of problems}




\subsubsection{Ignorance of the rigid demands of tourism body}

There is a deviation between law of tourism, tourism or biased understanding, including more development and interpretation of landscape, land, and technical point of view, ignoring the leisure and tourism body - the tourists. For tourists, the rustic charm of a country park meets more curious nature adventure of visitors. The number of tourists will not be decreased because of construction imperfections. Country Park should have basic facilities.

\subsubsection{Conflicts between ecological conservation and tourism development}

First, the overall outcome is the development planning of the premise of ecological protection. Ecological protection is the most important and prominent, including landscape value evaluation, which is carried out in this context. But for country parks, tourism and leisure is one of the very important aspects. It is also very critical in term of the perspective of tourism, interpretation and understanding of tourism resources with ecological protection needs, enhancing the overall resort.

\section{Country park planning design ideas and suggestions}

\subsection{Combination of construction planning and tourism planning}

The voices of commercial development and ecological protection have always existed. The concept of tourism project is in line with the current trend of tourism development. Considerations on forest protections fields and self driving camps are in line with the country's current tourism and leisure orientation, which is conductive for new tourism formats. After many years of exploration, ecological protection has become as the consensus of the community, when it comes to selecting between economic development and ecological protection. However touristic services tend to decline in its quality as ecological protection is chosen as the main construction and design criterion. Thus, when choosing between constructing a purely ecological protection park and a country park with tourism planning, the latter tend to be more beneficial.

\subsection{Improvements on touristic infrastructures}

\subsubsection{Traffic facilities}

Urban public transport should be enhanced in country park planning. Convenient external traffic can reduce the damage of self driving to the ecological environment. The key point is to focus on the coordination of "walking", "bicycles", and "vehicles" travel routes. In country park area, excluding necessary highway systems, walking and cycling routes should be prioritized. On the walk routes, there should be an exit in connection with public transport after every 4 hours of walk. In Shenzhen country parks, especially on mountains and hills, taking in consideration the age groups of visitors and the activities, trail slopes are designed as a combination of high oxygen level trails and medium oxygen level trails; flat hills can have low oxygen level trails.

\subsubsection{Service facilities}

Due to the large area of country parks, the number and location of service facilities are worth studying. Environmental facilities and rest facilities should be equipped within a certain radius of service. According to the tourism plan, country tours include half-day tours and full day tours. Catering facilities can be located in the terminal, designed for public consumption. Temporary supply points can be set up in halfway. 


\subsubsection{Safety facilities}

Compared to city parks, more attention should be paid to country parks when it comes to safety hazards. Getting lost, falls, wild animal attacks, and fire are all potential disasters. In addition to the inconveniency in transportation, rescue operations are more difficult to execute. Thus, country parks should have enough necessary guide sign systems and safety relief facilities. If the economic conditions allow, intelligent monitoring systems can also be set up.

\subsection{Overall Tourism Experience Structure}

It is very important to make the tourism planning and the selection of the tourism projects in the country park planning (Table 3). It is beneficial to the rational use of ecological protection, tourism resources and sustainable development. Tourism implementation strategy (Table 4) is helpful to determine the functional zoning, the environmental capacity, the amount of tourists, and the method, routes, and contents of the visits.

Table 3. Country Tourism Planning

\begin{tabular}{|c|l|}
\hline Experience System & \multicolumn{1}{c|}{ Plan } \\
\hline Brand building & $\begin{array}{l}\text { The characteristics of country parks and meticulous service are the } \\
\text { foundation of brand building. }\end{array}$ \\
\hline Atmosphere creation & $\begin{array}{l}\text { Sports experience time, forest vacation time, green road and } \\
\text { countryside time, culture and art time, business communication time. }\end{array}$ \\
\hline Carrier Support & $\begin{array}{l}\text { Mountaineering, fitness, education, rest, gathering, landscape } \\
\text { viewing, natural education, ecological experience, forest health care, } \\
\text { etc. }\end{array}$ \\
\hline Spatial distribution & $\begin{array}{l}\text { Hiking routes can be set in the buffer zone of the ecological } \\
\text { protection zone. Cycling sports leisure area, red cultural leisure area, } \\
\text { service area, and other services can be set up in the Kang Le } \\
\text { recreation area. }\end{array}$ \\
\hline
\end{tabular}

Table 4. Implementation strategy of country tourism

\begin{tabular}{|c|c|c|}
\hline \multicolumn{2}{|c|}{ System Analysis } & Implementation Strategy \\
\hline Travel Time & & $\begin{array}{l}\text { Mainly half-day tours and full-day tours. In order to } \\
\text { reduce the number of service facilities constructed, two } \\
\text { day tours or more should preferably not considered. }\end{array}$ \\
\hline & Hardware & $\begin{array}{l}\text { Strengthen the construction of service facilities } \\
\text { Perfect the slow green routes and the standard cycling } \\
\text { trails. }\end{array}$ \\
\hline $\begin{array}{l}\text { Tourism } \\
\text { Connotation }\end{array}$ & Software & $\begin{array}{l}\text { - construction of natural education path; meet the natural } \\
\text { experience } \\
\text { integration of environmental science education; } \\
\text { development of Forest Recreation } \\
\text { establishment of ecological protection base; protection } \\
\text { of endangered plants } \\
\text { Creation of environmental education base; raise } \\
\text { awareness on environmental protection } \\
\text { Linkage to the community comprehensive } \\
\text { development; Highlights on the participation in } \\
\text { projects }\end{array}$ \\
\hline
\end{tabular}




\begin{tabular}{|l|l|l|}
\hline \multirow{2}{*}{ Technical Support } & - Intelligent Management System/ Ma Luan Shan \\
& Intelligent Service System \\
& Intelligent Marketing System/ Ma Luan Shan \\
Intelligent Marketing System \\
Intelligent Environmental System
\end{tabular}

\section{References}

1. https://en.wikipedia.org/wiki/Country_park

2. http://www.szpl.gov.cn/main/csgh/zxgh/ldgh/fb.htm

3. Gao Xiangduo, Chen Ban, $\mathrm{Hu}$ Zhiliang, Chen Jishen. Recreational Space Planning In Countryside Park, Tianjin[S].Planners, 2015 (11) : 63-66

4. http://www.szpl.gov.cn/main/csgh/zxgh/ldgh/ft77.htm

5. FANG Jia, WANG De, ZHU Wei, SONG Shan, Residents' Recreation Preference of the Country Park in Shanghai: A Stated-preference Analysis, Chinese Landscape Architecture, [J],2016(4):5055

6. SHANG Feng-biao, ZHOU Wu-zhong .

Country Park Development Analysis and System Construction Based on Visitor Demands Journal of Northwest Forestry University, 2009(1): 199-203.

7. Zhu Jiang. Country park planning in China: a case study of four cities in Hongkong, Shenzhen, Beijing and Shanghai [D].Beijing: China Academy Of Urban Planning and Design, 2010. 